\title{
Investigation of Silicon Sensor Quality as a Function of the Ohmic Side Processing Technology
}

\author{
P. Bloch, A. Cheremukhin, S. Golubkov, I. Golutvin, N. Egorov, K. Konjkov, Y. Kozlov, A. Peisert, A. Sidorov, and \\ N. Zamiatin
}

\begin{abstract}
Silicon sensors designed for the CMS Preshower detector must have a high breakdown voltage in order to be fully efficient after irradiation to $2 \times 10^{14} \mathrm{n} / \mathrm{cm}^{2}$ expected during the ten years of large hadron collider operation (CMS ECAL Group, Bloch et al.). Studies made by several groups (Bischoff $e t$ al., Evensen et al., Da Rold et al., Passeri et al., Li et al., Militaru et al.) have underlined the importance of the $\mathrm{p}^{+}$side geometrical parameters, such as the metal width and the number and spacing of guard rings. We have in addition investigated the effects related to the ohmic side processing and found that the breakdown voltage depends strongly on the thickness of the effective "dead" $n+$ layer. By increasing this thickness from 1 to $2.5 \mu \mathrm{m}$, the fraction of sensors with breakdown voltage higher than $500 \mathrm{~V}$ increased from $22 \%$ to more than $80 \%$. In addition, a thick $n^{+}$layer protects against defects caused by the technological treatment during detector production and assembly.
\end{abstract}

Index Terms-Breakdown voltage, ohmic contact, radiation hardness, silicon sensor.

\section{INTRODUCTION}

$\mathbf{S}$ ILICON surface defects, crystal lattice distortions and unsaturated bonds, act as generation-recombination centers. Generated charge diffuses into the $\mathrm{n}^{+}$layer and enters the spacecharge region of a fully depleted sensor, thus contributing to the leakage current and reducing the breakdown voltage.

An attempt to reduce the density of the crystal defects by polishing the wafers on the $\mathrm{n}^{+}$side, followed by a chemical etching, was unsuccessful. Single- and double-sided polished wafers were processed in the same run, and the average leakage current and the breakdown voltage were the same for both groups of sensors [2].

The quantity of charge carriers that diffuse to the depletion region depends on their lifetime and on the diffusion length. The longer the lifetime and the diffusion length, the more the charge will be able to reach the space charge region and contribute to the leakage current.

The diffusion length and the lifetime of minority carriers are a strong function of the phosphorus atom concentration. Increasing this concentration from $10^{19}$ to $10^{20} \mathrm{~cm}^{-3}$ decreases the lifetime by two orders of magnitude to below $500 \mathrm{ps}$ [10]. Minority carriers (holes) with such a short lifetime recombine

Manuscript received February 13, 2001; revised October 26, 2001.

P. Bloch and A. Peisert are with CERN, 23 Geneva, Switzerland (e-mail: Philippe.Bloch@cern.ch; Anna.Elliott-Peisert@cern.ch).

A. Cheremukhin, I. Golutvin, and N. Zamiatin are with JINR, 141890 Dubna, Russia (e-mail: Zamiatin@sunse.jinr.ru).

S. Golubkov, N. Egorov, K. Konjkov, Y. Kozlov, and A. Sidorov are with RIMST, ELMA, Zelenograd, Russia.

Publisher Item Identifier S 0018-9499(02)01831-2. before reaching the space region and do not contribute to the leakage current.

Another processing parameter, the $\mathrm{n}^{+}$layer thickness, is also crucial. The thicker it is, the less the charge generated at the silicon surface will be able to reach the space-charge zone by diffusion.

We expect the leakage current at voltages beyond full depletion to be reduced, and the breakdown voltage to increase, if we find a way to increase the thickness of the $n^{+}$layer and to decrease the carrier lifetime by increasing the dopant concentration.

We have investigated two methods allowing an increase of the $\mathrm{n}^{+}$layer thickness: diffusion and implantation with a diffusion annealing. They both give the desirable improvement, but for technical reasons (see Section II) we concentrated on the second method. This method also enabled us to increase the phosphorus atom concentration and to reduce the minority carriers' lifetime, but no measurements are available yet.

In this paper, Section II describes the two technologies, compared to a standard implantation, used in the past. In Section III, we propose a fast, nondestructive method for measurement of the effective "dead" layer, which we define as a layer in which the generated charge or charge passing through it recombines and is lost. In Section IV, we present the obtained results. In Section V, we give a summary and the conclusions.

\section{Ohmic Contact Technology}

Silicon sensors used in high-energy physics are made either by ion implantation or by diffusion. Implantation is a fast method but gives shallow $(\leq 1 \mu \mathrm{m})$ contacts with a maximum dopant concentration of less than $10^{20} \mathrm{~cm}^{-3}$.

Contacts made by diffusion have higher dopant concentrations and can have a depth reaching $10 \mu \mathrm{m}$, but they require a very long, high-temperature process.

We developed a third method for making the ohmic contact that is a combination of the two, which we call implantation with diffusion annealing. It does not require a long, high-temperature process. The parameters used in this process are listed in Table I, together with the parameters of standard implantation and diffusion that we used to produce our samples.

In all three cases, we used phosphorus doping. In all of our production, the ohmic side was processed first. The junction side was processed in the same way on all samples described in this paper. It was implanted with boron at $35 \mathrm{keV}$ to a total fluence of $0.8 \times 10^{15}$ ions $/ \mathrm{cm}^{2}$ with a resulting surface resistivity of $200 \Omega /$ square. 
TABLE I

PARAMETERS CHARACTERISTIC FOR STANDARD IMPLANTATION, DIFFUSION AND IMPLANTATION WITH DIFFUSION ANNEALING

\begin{tabular}{l|l|l|l}
\hline & $\begin{array}{c}\text { Stand. } \\
\text { implant } \\
\text { ation }\end{array}$ & Diff. & $\begin{array}{l}\text { Impl. } \\
\text { with } \\
\text { diff. } \\
\text { ann. }\end{array}$ \\
\hline \hline $\mathrm{E} \mathrm{(keV)}$ & 100 & & 100 \\
\hline $\begin{array}{l}\text { Fluence } \\
\text { (ions/cm }\end{array}$ & $3 \times 10^{15}$ & $1.5 \times 10^{17}$ & $6 \times 10^{15}$ \\
\hline $\begin{array}{l}\mathrm{R}_{\mathrm{s}} \\
(\Omega / \mathrm{square})\end{array}$ & 40 & 1.3 & 30 \\
\hline $\begin{array}{l}\text { Annealing } \\
\text { time and temp. }\end{array}$ & $0.5 \mathrm{~h}$ & $7 \mathrm{~h}$ & $3 \mathrm{~h}$ \\
\hline Gas & $\mathrm{N}_{2}$ & $1100^{\circ} \mathrm{C}$ & $1100^{\circ} \mathrm{C}$ \\
\hline
\end{tabular}

\section{EfFective “DeAD” LAYer Measurement}

The secondary ion mass spectrometry (SIMS) method is a precise way of measuring the concentration of elements, but it has three drawbacks: it is very expensive, it is destructive, and it only gives the concentration of atoms without indicating their electrical activities. Only electrically active dopants are effective as generation-recombination centers.

We have developed a fast, nondestructive method of measuring the thickness of the effective "dead" layer. It relies on a precise measurement of the energy lost by an $\alpha$ particle in silicon and on comparing it with a calculated value.

\section{A. The Setup}

The measurements were made using an Amptek 250 preamplifier and shaper with a shaping time of $500 \mathrm{~ns}$ and an equivalent noise charge of about $800 \mathrm{e}^{-}$. The electronics chain, including a 12-bit analog-to-digital converter (ADC), was calibrated using test pulses. The conversion factor was $2.2 \mathrm{keV}$ for one $\mathrm{ADC}$ count. The measured energy resolution was $30 \mathrm{keV}$.

We used the ${ }^{226} \mathrm{Ra} \alpha$ source with four lines at 4.781, 5.486, 6.00 , and $7.688 \mathrm{MeV}$.

\section{B. The Sensors}

The measurements were made with silicon sensors designed for the CMS Preshower [2]. They have a total volume of $63 \times$ $63 \times 0.3 \mathrm{~mm}^{2}$, with $32 \mathrm{p}^{+}$strips, $1.8 \mathrm{~mm}$ wide, with a gap between them of $0.1 \mathrm{~mm}$. Fig. 1(a) and (b) shows schematically the cross-section along a strip and the top view of an element of the sensor, respectively.

The aluminum lines are $\mathrm{dc}$ connected to the $\mathrm{p}^{+}$implant through an array of feedthroughs. They have openings, $1.5 \times$ $2 \mathrm{~mm}^{2}$, designed for tests with an infrared laser. The design value of the $\mathrm{p}^{+}$implant thickness is $0.3 \mu \mathrm{m}$. The oxide between the $\mathrm{p}^{+}$implant and the aluminum is $0.2 \mu \mathrm{m}$ thick and the aluminum thickness is $0.8 \pm 0.1 \mu \mathrm{m}$ on both sides of the sensor.

The junction side was designed following the rules to obtain a high breakdown voltage. The aluminum strips are $20 \mu \mathrm{m}$ wider than the $\mathrm{p}^{+}$implants, and all strips and guard rings have rounded

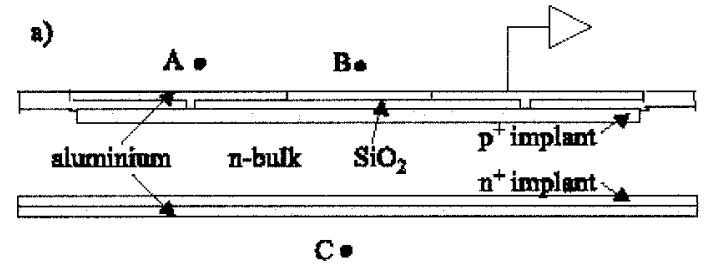

b)

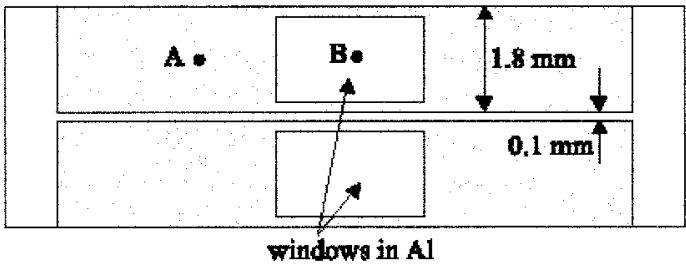

Fig. 1. Setup for measuring the effective "dead" layer thickness using an $\alpha$ source. (a) Cross-section along a strip. (b) Top view of an element of the sensor.

TABLE II

DIFFERENTIAL ENERGY LOSS IN SILICON AND ALUMINUM AND RANGE IN Silicon FOR Four ENERGIES OF $\alpha$ PARTICLES FroM ${ }^{226}$ Ra SOURCE

\begin{tabular}{l|l|l|l|l}
\hline $\begin{array}{c}\mathrm{E}(\alpha) \\
(\mathrm{MeV})\end{array}$ & 4.781 & 5.486 & 6.00 & 7.688 \\
\hline \hline $\begin{array}{l}\mathrm{dE} / \mathrm{dx}(\mathrm{Si}) \\
(\mathrm{keV} / \mu \mathrm{m})\end{array}$ & 153.5 & 139.2 & 131.4 & 111.3 \\
\hline $\begin{array}{l}\mathrm{dE} / \mathrm{dx}(\mathrm{Al}) \\
(\mathrm{keV} / \mu \mathrm{m})\end{array}$ & 171.6 & 155.4 & 147.9 & 123.8 \\
\hline $\begin{array}{l}\text { Range in Si } \\
(\mu \mathrm{m})\end{array}$ & 23 & 28 & 32 & 47 \\
\hline
\end{tabular}

corners. These two features are known to reduce the field at the edge of the strip [7], resulting in a higher breakdown voltage.

A series of four guard rings surrounds the active strips. Their number, width, and spacings were optimized to have a uniform gradient of the field. The guard rings are left floating during the measurements.

\section{The Method}

An $\alpha$ particle entering the sensor loses energy in the aluminum, in the silicon dioxide, and in the depleted silicon. Charge generated in aluminum, in $\mathrm{SiO}_{2}$, and in the implanted layer, $\mathrm{n}^{+}$or $\mathrm{p}^{+}$, recombines and is lost, while charge released in the space-charge region is detected.

Three measurements were taken with the source positioned on top of the aluminum ( $A$ in Fig. 1), on top of the opening in the aluminum $(B)$, and on the ohmic side $(C)$. The source was collimated with a 1 -mm-thick plastic foil with a 1-mm-diameter hole.

The energies $E(A), E(B)$, and $E(C)$, measured with the source positioned in $A, B$, and $C$, are

$$
\begin{aligned}
& E(A)=E(\alpha)-\Delta E\left(\mathrm{p}^{+}\right)-\Delta E(\mathrm{Al})-\Delta E\left(\mathrm{SiO}_{2}\right) \\
& E(B)=E(\alpha)-\Delta E\left(\mathrm{p}^{+}\right)-\Delta E\left(\mathrm{SiO}_{2}\right) \\
& E(C)=E(\alpha)-\Delta E\left(\mathrm{n}^{+}\right)-\Delta E(\mathrm{Al})
\end{aligned}
$$




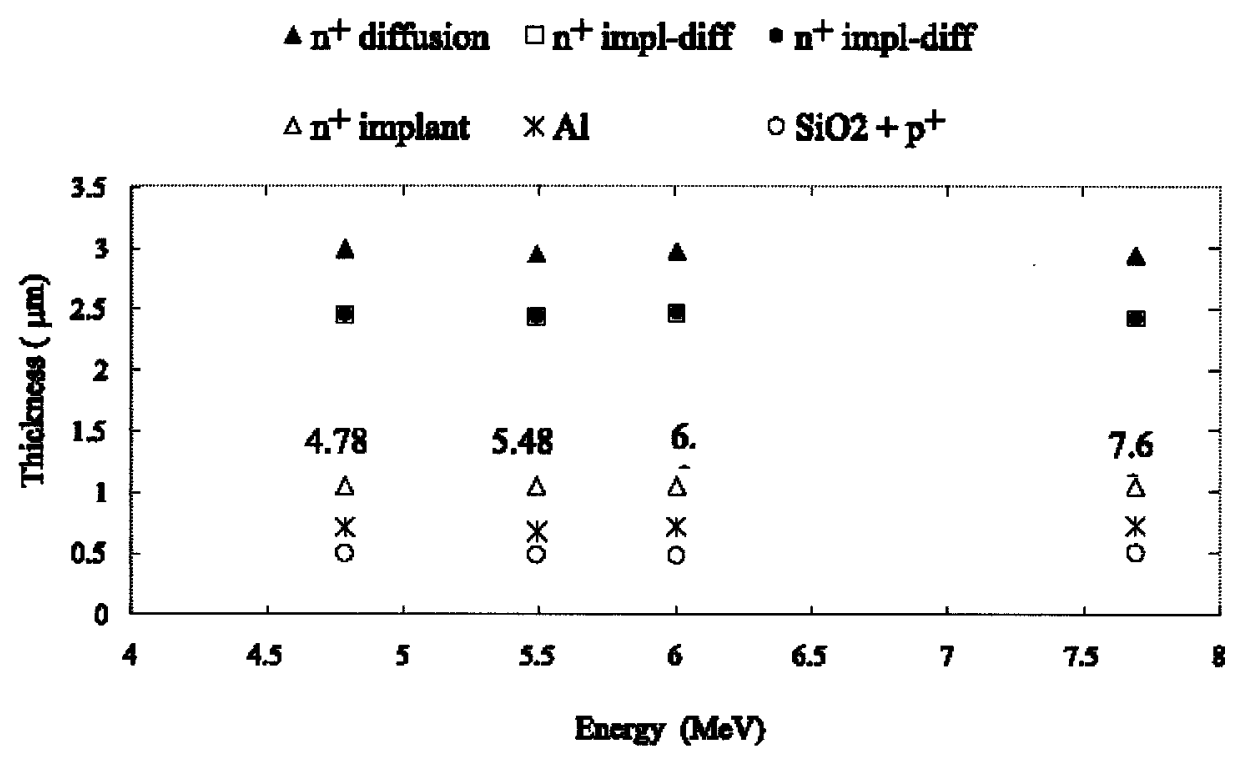

Fig. 2. Thickness of effective "dead" layer for the $\mathrm{n}^{+}$implant of the three different technologies for the $\mathrm{Al}$ strip metallization and for the $\mathrm{p}^{+}$and $\mathrm{SiO}_{2}$ layers.

where $E(\alpha)$ is the total energy of the particle, $\Delta E\left(\mathrm{p}^{+}\right)$and $\Delta E\left(\mathrm{n}^{+}\right)$are the energy lost in the $\mathrm{p}^{+}$and $\mathrm{n}^{+}$implants, respectively, $\Delta E(\mathrm{Al})$ is the energy lost in the aluminum, and $\Delta E\left(\mathrm{SiO}_{2}\right)$ is the energy lost in the oxide.

The energy lost in the aluminum can be calculated from (1) and (2). Using the differential energy loss in aluminum, listed in Table II for four $\alpha$ particle energies [10], [11], one obtains an average thickness of about $0.7 \mu \mathrm{m}$, in good agreement with the specified $0.8 \pm 0.1 \mu \mathrm{m}$.

The energy lost in the silicon dioxide and in the $\mathrm{p}^{+}$implanted layer is obtained from (2). To calculate the total thickness of these two layers, we assume that the differential energy loss in $\mathrm{SiO}_{2}$ is the same as in the silicon. This assumption is justified by the fact that the differential energy loss in $\mathrm{O}_{2}$ and the density of $\mathrm{SiO}_{2}$ are very close to those of silicon. We obtain the total thickness of $\mathrm{SiO}_{2}+\mathrm{p}^{+}$of about $0.5 \mu \mathrm{m}$, which corresponds to $0.2 \mu \mathrm{m}$ of $\mathrm{SiO}_{2}$ and $0.3 \mu \mathrm{m}$ of $\mathrm{p}^{+}$as expected (see Section III-B).

Once one knows the energy lost in the aluminum, the thickness of the effective "dead" $\mathrm{n}^{+}$layer can be directly calculated from (3), using the $d E / d x(\mathrm{Si})$ values from Table II.

Calculating the energy lost in the aluminum, in silicon and in the silicon dioxide, we assume that the energy of $\alpha$ particles is constant. This assumption is justified by the fact that these media are thin and that the energy loss is relatively low compared to the total energy of the $\alpha$ particle (3.2\% for the lowest energy) (see Table II).

The measurement was made on four samples: one produced by standard implantation, one produced by diffusion, and two produced using the implantation with diffusion annealing method.

Fig. 2 shows the thickness of the effective "dead" $\mathrm{n}^{+}$and $\mathrm{p}^{+}$ layers, obtained from (2) and (3). One sees that the measurements at four different energies of $\alpha$ particles give consistent results among them. Fig. 2 also shows the thickness of the aluminum layer and the combined thickness of $\mathrm{SiO}_{2}$ and the $\mathrm{p}^{+}$ implant.

\section{PRoduction Results}

The results presented in the previous section show that one can obtain a relatively deep $\mathrm{n}^{+}$layer in a process that is less time- and power-consuming than the diffusion. We expect that sensors produced using this technology would suffer less from backplane injection and would have a higher breakdown voltage than those produced by standard implantation.

Two series of 50 and 60 sensors were produced using a standard implantation method and implantation with diffusion annealing with the resulting effective "dead" layer thicknesses of 1 and $2.5 \mu \mathrm{m}$, respectively. The junction side was processed in exactly the same way on both groups of sensors. Their geometry was described in the previous section. They were made on a 3 to $4 \mathrm{k} \Omega \mathrm{cm}$ substrate produced by Topsil. The full depletion voltage of these sensors was between 80 and $100 \mathrm{~V}$.

The sensors were processed in several small batches of 12-13 wafers. About $10 \%$ of wafers were lost due to mechanical defects during production and/or cutting. Our earlier studies of the junction side processing showed that the breakdown starting at the $\mathrm{p}^{+}$side is characterized by a very steep current increase accompanied by microdischarges, clearly visible with the naked eye in a dark room. To be able to compare the effects of the n-side processing only, we rejected sensors showing microdischarges on the $\mathrm{p}^{+}$side, about $30 \%$ for both groups. The remaining $60 \%$ of sensors, 30 and 36 for 1 and $2.5 \mu \mathrm{m}$, respectively, are the subject of this study.

Figs. 3 and 4 show the total leakage current as a function of bias voltage for the standard implantation and for implantation with diffusion annealing, respectively. The measurement was made at $20{ }^{\circ} \mathrm{C}$ and a relative humidity of about $50 \%$. The bias voltage was applied to the ohmic side, and all the strips were grounded. The voltage was changed in steps of $25 \mathrm{~V}$ with a ramp of about $50 \mathrm{~V} / \mathrm{s}$.

One sees that although the average current at the full depletion voltage is about $100 \mathrm{nA}$ for both groups of sensors, there is a big difference in the breakdown voltages between these two technologies. 


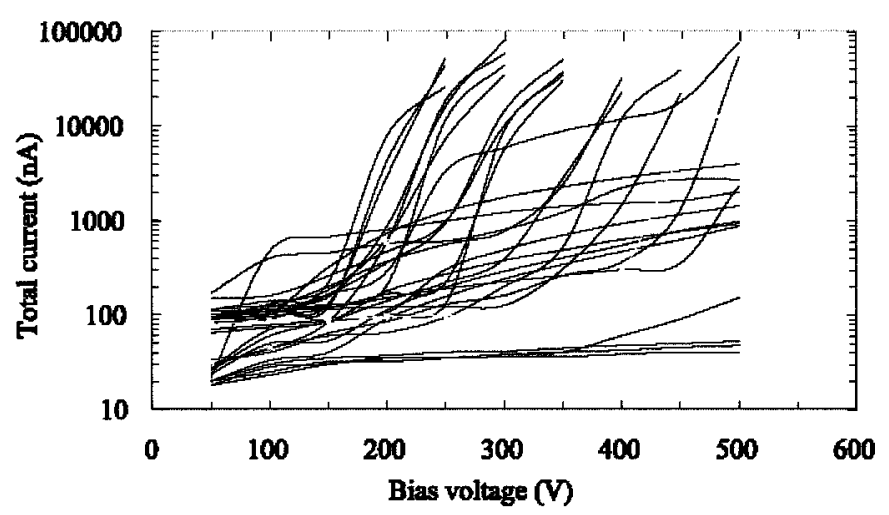

Fig. 3. Total leakage current for $1-\mu$ m-thick effective "dead" $n^{+}$layer sensors produced by standard implantation.

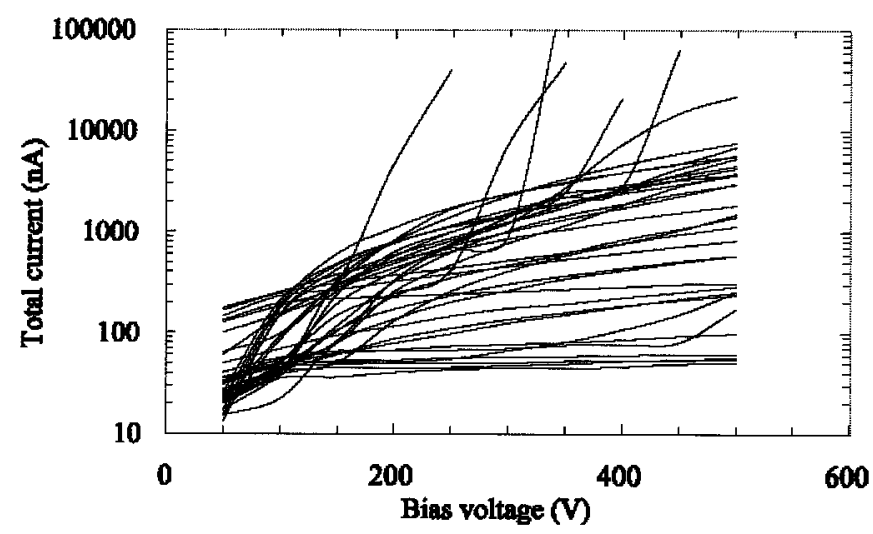

Fig. 4. Total leakage current for $2.5-\mu$ m-thick effective "dead" $\mathrm{n}^{+}$layer sensors produced by implantation with diffusion and annealing.

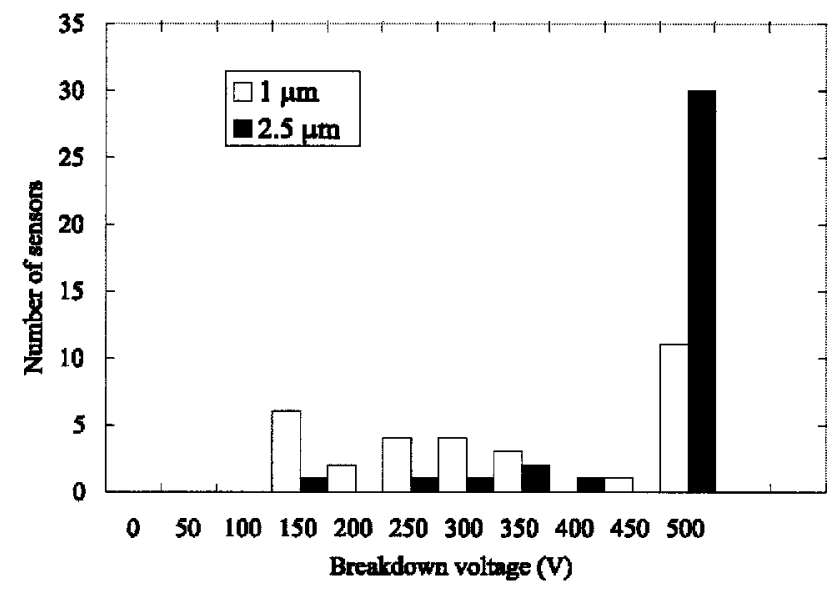

Fig. 5. Breakdown voltage histogram for sensors produced by standard implantation (open symbols) and by implantation with diffusion and annealing (close symbols) with 1 - and $2.5-\mu \mathrm{m}$ effective "dead" layer thickness, respectively.

Fig. 5 shows the breakdown voltage, defined as the voltage at which the relative current increase $\Delta I / \Delta V>1 \mu \mathrm{A} / \mathrm{V}$, for both groups of detectors, measured up to $500 \mathrm{~V}$. The improvement obtained with the thicker $\mathrm{n}^{+}$layer is clearly visible.

To further convince ourselves that the difference in the leakage current for the two groups of sensors comes from the $\mathrm{n}^{+}$side processing, we simulated a defect by scratching the

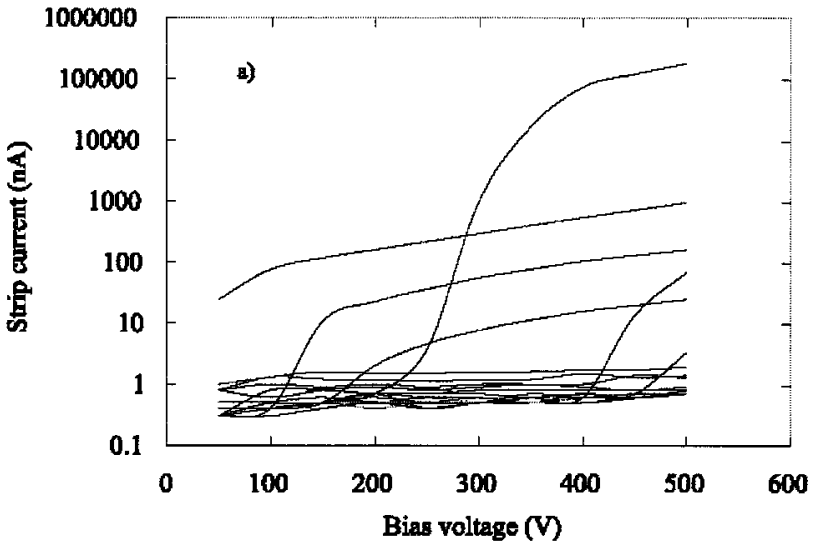

(a)

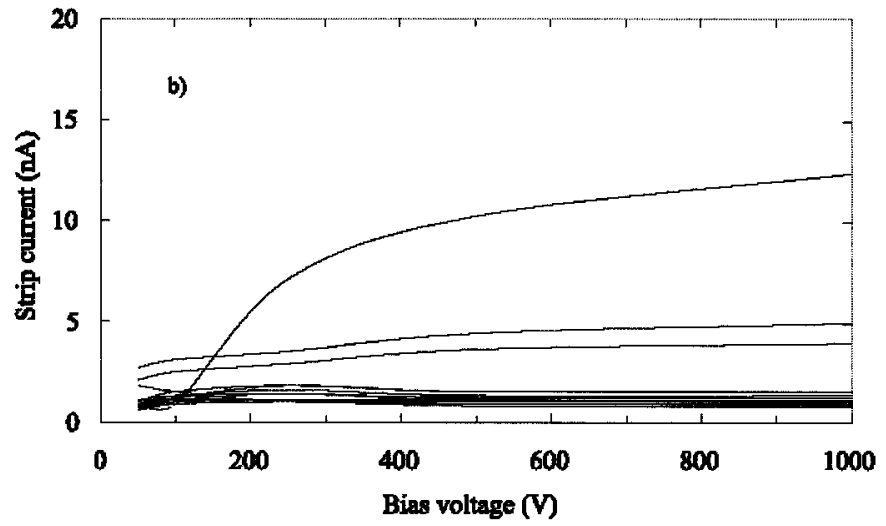

(b)

Fig. 6. Strip current (for 32 strips) as a function of bias voltage for two sensors: (a) with $1 \mu \mathrm{m}$ and (b) with $2.5 \mu \mathrm{m}$ of $\mathrm{n}^{+}$layer.

backplane with a diamond. This exercise produced an increase of the current similar to those in Fig. 3.

In view of the arguments presented so far, we are pretty confident that the improvement is due to the difference in the backplane processing technology.

Sensors with a thicker $\mathrm{n}^{+}$layer also have a more uniform distribution of current across the strips. Fig. 6 shows typical results of the strip current as a function of voltage for two sensors from the groups described above: (a) sensor with a $1-\mu$ m layer and (b) sensor with a 2.5- $\mu \mathrm{m}$ layer. The sensor in Fig. 6(a) was tested up to $500 \mathrm{~V}$ only because of the high current of one strip. The higher quality of the sensor with a $2.5-\mu \mathrm{m} \mathrm{n}^{+}$layer is clearly visible.

\section{SUMMARY AND CONCLUSION}

We have investigated the quality of silicon sensors as a function of the ohmic side processing. We found that a deep $\mathrm{n}^{+}$layer prevents the charge generated at the silicon surface from diffusing into the space-charge region at high voltages. The result is a higher breakdown voltage compared to a thin $\mathrm{n}^{+}$layer. A thick layer can be produced either by diffusion - a long and high-temperature process - or by implantation with diffusion annealing, requiring a shorter high-temperature step. Using this method, we obtain an $\mathrm{n}^{+}$layer thickness of $2.5 \mu \mathrm{m}$, and more than $80 \%$ of sensors have a breakdown voltage higher than $500 \mathrm{~V}$. 


\section{REFERENCES}

[1] The CMS ECAL Group, "The electromagnetic calorimeter project technical design report,", CERN/LHCC 97-33, 1997.

[2] Ph. Bloch, Y.-H. Chang, A. E. Chen, A. Cheremukhin, N. Egorov, and A. Go et al., "Silicon sensors for the CMS Preshower detector," Nucl. Instrum. Methods, vol. A, Apr. 2000, to be published.

[3] A. Bischoff, N. Findeis, D. Hauff, P. Holl, J. Kemmer, and P. Klein et al., "Breakdown protection and long-term stabilization for Si-detectors," Nucl. Instrum. Methods, vol. A326, pp. 27-37, 1993.

[4] L. Evensen, A. Hanneborg, B. Avset, and M. Nese, "Guard ring design for high voltage operation of silicon detectors," Nucl. Instrum. Methods, vol. A337, pp. 44-52, 1993.

[5] M. Da Rold, A. Paccagnella, A. Da Re, G. Verzellesi, N. Bacchetta, and R. Wheadon et al., "Radiation effects on breakdown characteristics of multiguarded devices," IEEE Trans. Nucl. Sci., vol. 44, pp. 721-727, June 1997.

[6] M. Da Rold, N. Bacchetta, D. Bisello, A. Paccagnella, G.-F. Dalla Betta, and G. Verzellesi et al., "Study of breakdown effects in silicon multiguard structures," IEEE Trans. Nucl. Sci., vol. 46, pp. 1215-1223, Aug. 1999 .
[7] D. Passeri, P. Ciampolini, A. Scorzoni, and G. M. Bilei, "Physical modeling of silicon micro-strip detectors: Influence of the electrode geometry on critical electric field," IEEE Trans. Nucl. Sci., vol. 47, pp. 1468-1473, Aug. 2000

[8] Z. Li, W. Huang, and L. J. Zhao, "Study of the correlation between cutting edge current breakdown and the simulated lateral electrical field boundary in high resistivity silicon detectors with multiguard ring structure," IEEE Trans. Nucl. Sci., vol. 47, pp. 729-736, June 2000.

[9] O. Militaru, L. Borrello, C. Bozzi, M. Da Rold, R. Dell'Orso, and S. Dutta et al., "Study of edge effects in the breakdown process of $\mathrm{p}^{+}$on n-bulk silicon diodes," Nucl. Instrum. Methods, vol. A 439, pp. 262-269, 2000

[10] A. Rohatgi and P. Rai-Choudhury, "Design, fabrication and analysis of 17-18 percent efficient surface passivated silicon solar cells," IEEE Trans. Electron. Devices, vol. ED-31, pp. 596-600, 1984.

[11] E. Segre, Experimental Nuclear Physics New York, 1953, vol. 1.

[12] F. Willianson, J. P. Boujot, and J. Picard, "Tables of range and stopping power of chemical elements for charged particles of energy 0.05 to 500 $\mathrm{MeV}$, , in Rapport CEA N3042, Saclay, France, 1966. 